\title{
Effects of divertor geometry and chemical sputtering on impurity behaviour and plasma performance in JET
}

\author{
H.Y. Guo*a, G.F. Matthews, I. Coffey, S.K. Erents, M. Groth ${ }^{\text {, }}$ \\ P.J. Harbour, M.G. von Hellermann, D.L. Hillis ${ }^{c}$, J.T. Hogan ${ }^{\text {d }, ~ L . D . ~ H o r t o n, ~}$ \\ L.C. Ingesson, K.D. Lawson, J. Lingertat, C.F. Maggi, G.M. McCracken, \\ R.D. Monk, P.D. Morgan, M.F. Stamp, P.C. Stangeby ${ }^{\mathrm{d}}$, A. Taroni, \\ G.C. Vlases ${ }^{\mathrm{a}}$ \\ JET Joint Undertaking, \\ Abingdon, Oxfordshire, \\ United Kingdom
}

\begin{abstract}
The effects of increased geometrical closure on the behaviour of the recycling and intrinsic impurities are investigated in JET Mark I, Mark IIA and Mark IIGB pumped divertors. Increasing the divertor closure leads to a significant improvement in exhaust for both deuterium and recycling impurities. However, the impurity enrichment in the exhaust gases remains unchanged due to a simultaneous increase in deuterium and impurity compression in the divertor. A comparison is made for helium, neon and argon under different plasma conditions. In addition, the operation of the Mark II and Mark IIGB divertors has shown that $Z_{\text {eff }}$ is reduced with the improved divertor closure in the $\mathrm{L}$ mode discharges, although no obvious changes in the $Z_{\text {eff }}$ values have been observed in the ELMy $\mathrm{H}$ modes. The divertor target surface temperature has a strong influence on intrinsic carbon production. The carbon source in the Mark II and Mark IIGB divertors is significantly higher than that in the Mark I divertor, which is attributed to enhanced chemical sputtering at the increased divertor tile temperature of the Mark II and Mark IIGB divertors (related to the divertor cooling system), as opposed to the increased closure. The consequences of this elevated yield for plasmas under different operation conditions are discussed, and further evidence, obtained from a specific wall/divertor temperature reduction experiment, is presented. The effect of the divertor screening on the chemically produced impurities is investigated using the EDGE2D/NIMBUS/DIVIMP codes for the different recycling regimes and comparisons are made with experimental observations from the Mark I, Mark IIA and Mark IIAP divertors taking into account the change in chemical sputtering yield due to the different tile temperatures of these divertors.
\end{abstract}

\section{Introduction}

The principal objectives for operating pumped divertors are to provide sufficient particle exhaust for density control and to simultaneously maintain efficient screening for the impurities produced at the divertor target plates. In addition, pumping is essential for helium ash removal from a fusion reactor such as ITER $[1,2]$. Adequate exhaust of helium ash for

\footnotetext{
a Present affiliation: University of Washington, Seattle, Washington, USA.

b Present affiliation: University of Manchester (UMIST), Manchester, UK.

c Present affiliation: Oak Ridge National Laboratory, Oak Ridge, Tennessee, USA.

d Present affiliation: University of Toronto, Institute of Aerospace Studies, Toronto, Canada.

* Corresponding author: Redmond Plasma Physics Laboratory, University of Washington, Redmond, Washington, USA.
}

ITER requires the following criteria to be satisfied [2]:

(a) $\tau_{\alpha}^{*} / \tau_{E} \leq 10$, where $\tau_{\alpha}^{*}$ is the global alpha particle confinement time and $\tau_{E}$ is the energy confinement time;

(b) $\eta_{H e}=\left(p_{H e} / 2 p_{D_{2}}\right)_{d i v} /\left(n_{H e} / n_{e}\right)_{c o r} \geq 0.2$, where $\eta_{\mathrm{He}}$ is the helium enrichment factor, the ratio of the helium concentration in the divertor to the helium concentration in the core. This condition is required in order to reduce plasma dilution, to minimize the required pumping speed and to reduce tritium recirculation.

The impurity content of a plasma is determined by the impurity source distribution, as well as various transport processes of impurities in the SOL and the core plasma. For most materials, the dominant 


\section{H.Y. Guo et al.}

impurity production process is physical sputtering whilst for graphite, chemical sputtering has also proven to be important $[3,4]$. This has important implications for the divertor lifetime and tritium retention [5]. Both physical and chemical sputtering depend on the energy and the mass of the impinging species. In addition, chemical sputtering depends on surface temperature [6] and exhibits an uncertain flux dependence [7-13]. The divertor screening for the impurities relies on the large ion flow present in the divertor resulting from local flux amplification due to recycled neutrals, which drags impurities towards the divertor targets and opposes the thermal gradient force which tends to drive the impurity ions towards the main chamber $[14,15]$. Thus the divertor screening is sensitive to the background plasma conditions. In the normal high recycling regimes, the shielding for the divertor impurity source is strong and the wall source makes a significant contribution to core contamination [16], in contrast to the low recycling regime where impurity leakage from the divertor is important [17].

JET has investigated four pumped divertor configurations that have progressively increased geometrical closure, i.e. Mark I, Mark IIA/Mark IIAP and Mark IIGB $[18,19]$, to investigate the influence of divertor geometry on plasma performance under reactor relevant conditions. Mark IIAP is an upgraded version of the Mark IIA divertor with plugged leakage paths for neutrals between the subdivertor and the main chamber. Where no distinction is made between Mark IIA and Mark IIAP, Mark II refers to both divertors in the present article. The poloidal cross-sections of the Mark I, Mark II and Mark IIGB divertors are shown in Fig. 1. The operation of the Mark I and Mark II divertors allows either horizontal or vertical magnetic configurations with the divertor strike points placed on either the horizontal or vertical target plates. However, the Mark IIGB divertor, which has a septum structure located in the private flux region, permits only vertical (or corner) operation. The rationale underlining these series of experiments is discussed in Ref. [19] and can be summarized as follows. Increasing geometrical closure from Mark I to Mark IIA/AP to Mark IIGB was intended to increase the retention of neutrals in the divertor in the regime of high density divertor operation. The direct benefits of increased closure to neutrals were expected to increase neutral pressure in the divertor/subdivertor and to reduce the main chamber neutral fluxes. This in turn was expected to result in:
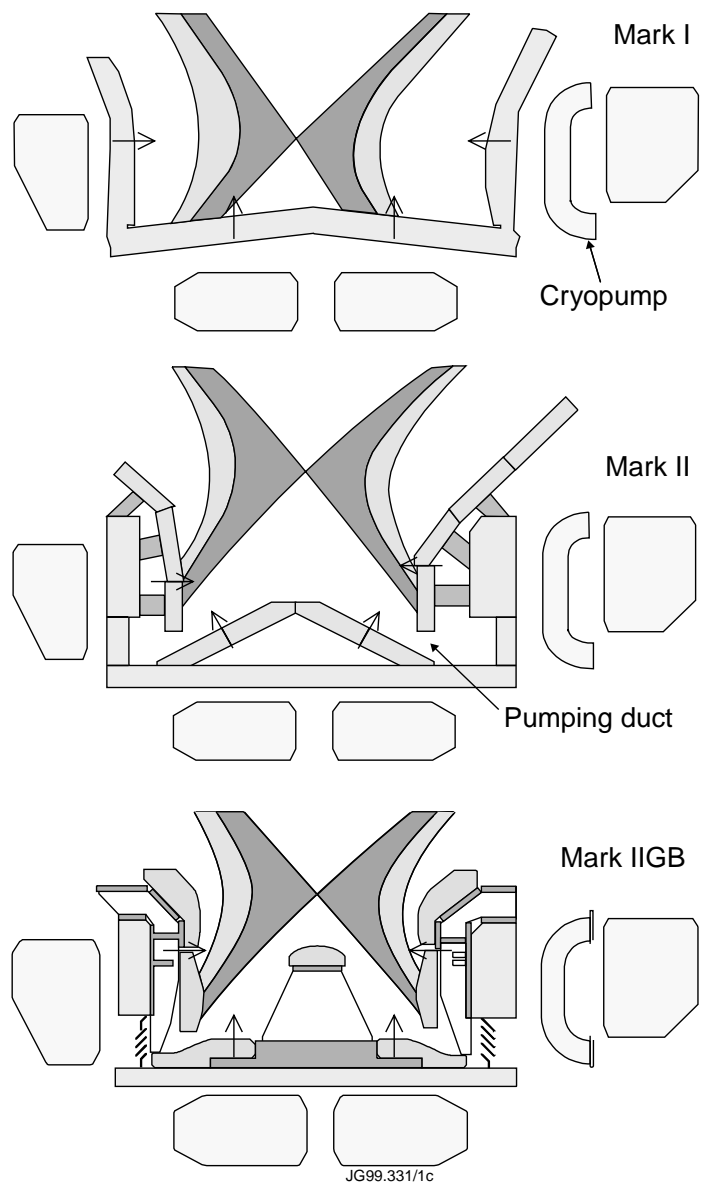

Figure 1. Poloidal cross-sections of the JET Mark I, Mark II and Mark IIGB pumped divertors. The locations of the gas inlets in the divertor region are shown by the arrows. The divertor cryopump and the pumping duct are also indicated. Note that the Mark I divertor target plate consisted of discrete tiles mounted along the toroidal direction with $1 \mathrm{~cm}$ gaps between tiles, which effectively served as the pumping ducts.

(a) Improved particle exhaust rate, which is necessary to control plasma density and to prevent helium accumulation in a fusion reactor;

(b) Reduced $Z_{\text {eff }}$ from intrinsic impurities as a result of reduced neutral particle sputtering in the main chamber;

(c) Easier access to detached regimes, thus reducing the divertor power loading and erosion at the targets;

(d) Improved confinement quality in ELMy $\mathrm{H}$ modes.

It should be pointed out that increased closure may lead to reduced parallel flow in the SOL due to reduced neutral recycling to the main chamber, 
resulting in poor removal of impurities from the main chamber. In steady state operation the improved exhaust rate must be balanced by additional particle input, usually introduced by external gas puffs, which could produce an excessive neutral source near the edge of the plasma, thus partly offsetting the effect of the closure. Furthermore, there may be problems from the interactions of ELMs with the components forming the narrow entrance of a closed divertor. In addition, there may be a source of impurities from the tokamak walls due to ion flux in the outer SOL which does not enter the divertor.

In going from the Mark I divertor to the Mark II divertor, one unexpected result is that the impurity production yield was increased by about a factor of two, as compared with that of Mark I. One possible explanation for this elevated sputtering yield is the enhanced chemical sputtering in Mark II due to the higher base temperature of the Mark II target plate. Water cooled rails kept the base temperature (before plasma shots) of the Mark I tiles to $\sim 40^{\circ} \mathrm{C}$, whereas in Mark II thermal isolation from the cooled substructure leads to a base temperature of $\sim 220^{\circ} \mathrm{C}$. Specific experiments with reduced wall and divertor temperatures were carried out with the Mark II divertor to address this issue.

In this article we present detailed studies of the influence of increased divertor closure on impurity exhaust and demonstrate the role of divertor surface temperature on impurity production and the consequences for plasma performance. Further results on the effect of divertor geometry from JET are given in Refs [19-21]. In outline the present article is as follows. In Section 2 we report the effects of increased geometrical closure on impurity exhaust and enrichment for the following recycling impurities: helium, neon and argon. The effect of the divertor closure on the intrinsic carbon impurity behaviour is also assessed. In Section 3 we attempt to explain the difference in the impurity production between the Mark I, Mark II and Mark IIGB divertors in terms of chemical sputtering and present further evidence coming from the wall/divertor temperature reduction experiments. The consequences of the elevated impurity yield for the plasmas under different operating conditions are discussed, hence demonstrating the significance of impurity production for plasma performance. In addition, the divertor screening efficiency for the impurities produced by physical and chemical sputtering processes is assessed for the different recycling regimes through detailed modelling using the EDGE2D/NIMBUS/DIVIMP

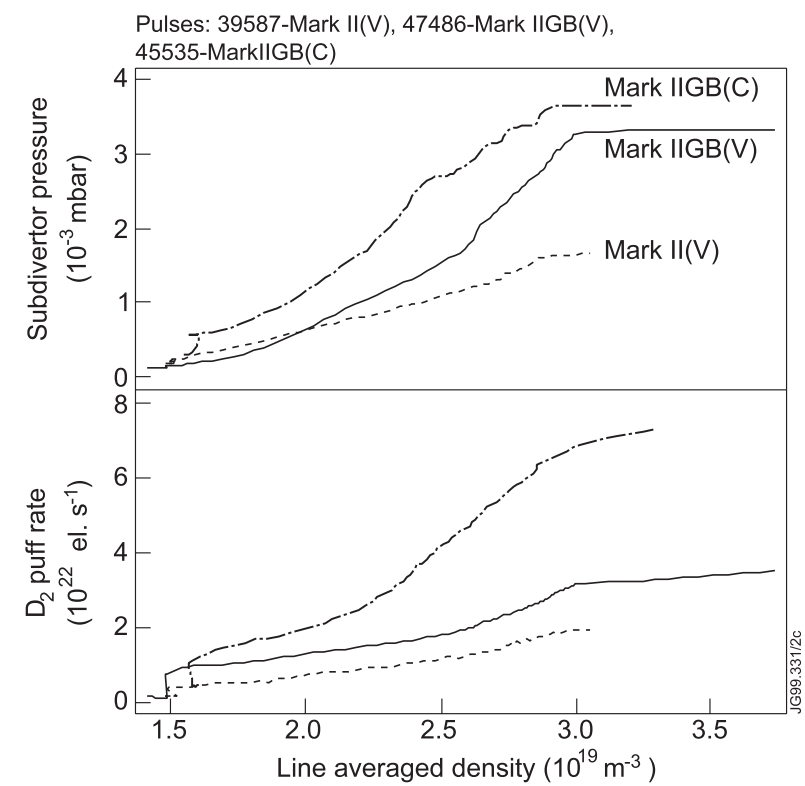

Figure 2. Subdivertor neutral pressures and gas injection rate for comparable L mode discharges in the Mark II and Mark IIGB divertors.

codes. A summary and conclusions follow in Section 4 .

\section{Effect of divertor geometry}

\subsection{Particle throughput}

Increasing the divertor closure in JET has led to a significant increase in the neutral pressure in the subdivertor (the volume below the divertor target), thus improving deuterium pumping. Consequently, more gas has to be injected to maintain similar plasma densities with increased divertor closure. To illustrate this, Fig. 2 shows the neutral pressure in the subdivertor volume, as well as the gas puff rate, as a function of the plasma line averaged density for L mode discharges in the Mark II and Mark IIGB divertors with different magnetic configurations. As expected, the divertor closure to the escape of neutrals is most effective in the regime of high plasma densities, i.e. in the high recycling non-detached regime where the electron temperature is relatively low and the density is high in the divertor so that the mean free paths of neutrals before ionization are small compared with the divertor geometric size. As can be seen, for the same vertical target configuration, indicated by $(\mathrm{V})$ in the figure, the divertor pressure in the Mark IIGB divertor is improved by nearly 


\section{H.Y. Guo et al.}

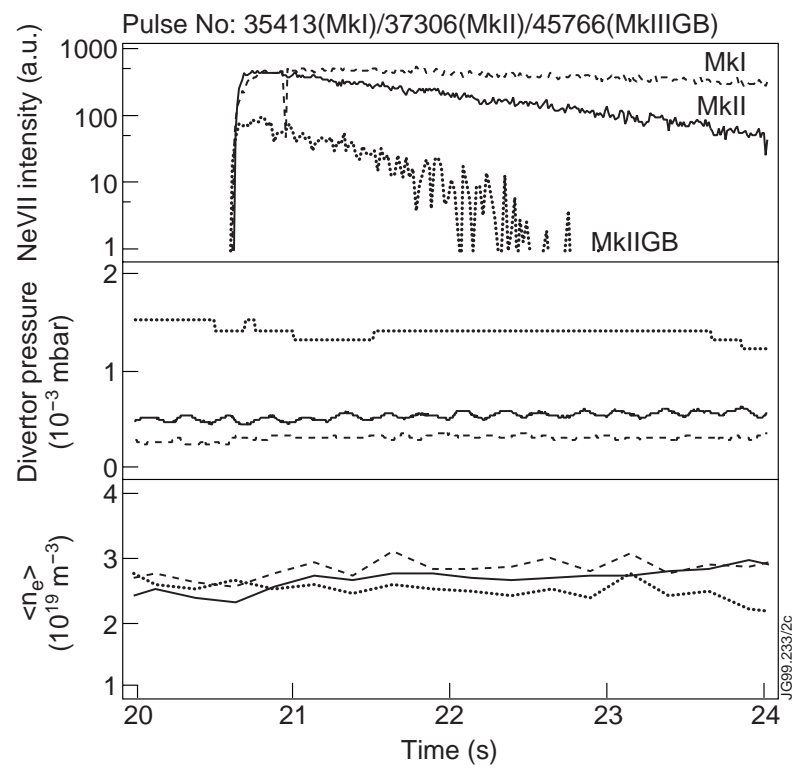

Figure 3. Time traces of $\mathrm{L}$ mode discharges in the Mark I, Mark II and Mark IIGB divertors, illustrating the changes in neon decay time following a short trace neon puff.

a factor of two at high densities. The pressure in the subdivertor volume is also dependent on the gas puff location [22] and the geometry of the strike points relative to the pumping ducts. A further improvement in the divertor exhaust rate was achieved in Mark IIGB with the corner configuration, (C) in the figure, where the strike points were placed next to the entrance of the pumping ducts. The difference in subdivertor pressure is less evident in the steady state ELMy $\mathrm{H}$ mode discharges due to the presence of ELMs [20].

\subsection{Impurity exhaust}

In order to investigate impurity exhaust, we have carried out a series of dedicated experiments in $\mathrm{L}$ mode plasmas using neon as a trace impurity. In these experiments, a small quantity of neon was puffed into the SOL to ensure that the perturbation of the background plasma was small. Figure 3 shows the evolution of Ne VII line intensity following a short neon puff into the SOL, together with the subdivertor pressure and the plasma density for the discharges carried out in the Mark I, Mark II and Mark IIGB divertors, respectively. The discharges have similar neutral beam heating power $(\sim 2 \mathrm{MW})$ and plasma density. It can be seen that the neon exhaust rate is improved with the increased

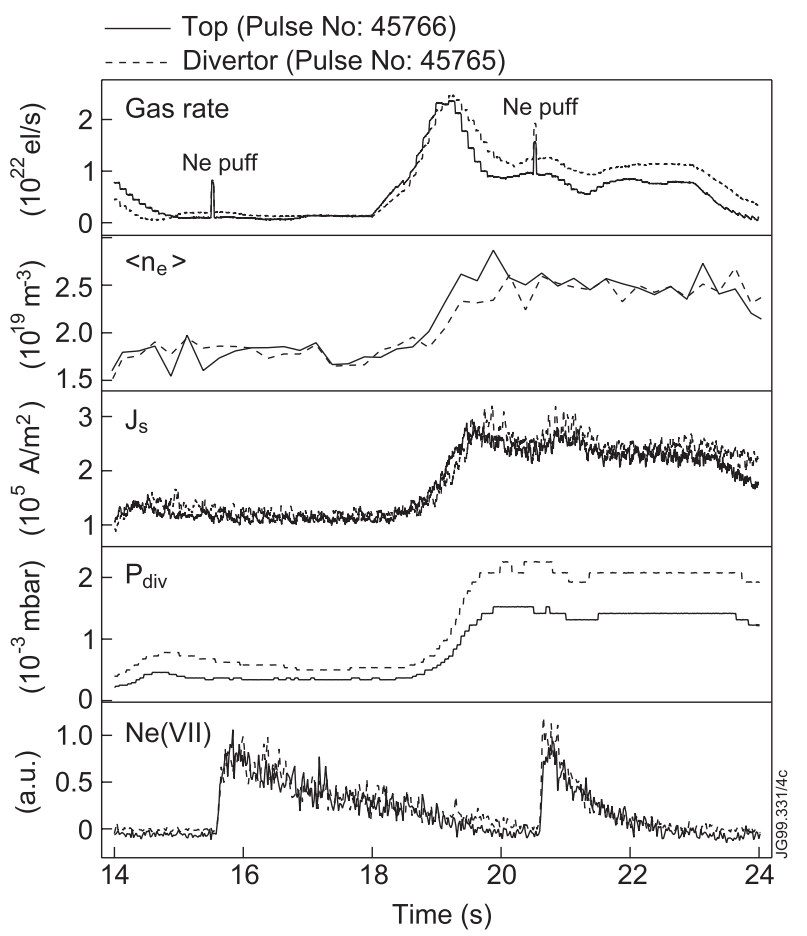

Figure 4. Time traces of two identical L mode discharges with $2 \mathrm{MW}$ of neutral beam heating, but with $\mathrm{D}_{2}$ fuelling from different locations. The data shown are the gas injection rate, the plasma volume averaged density, the ion saturation current measured by the target Langmuir probe located near the outer strike point, the subdivertor neutral pressure and the Ne VII (465.22 $\AA$ ) intensity.

divertor closure from Mark I to Mark II to Mark IIGB, and correlates with the progressive increase in the subdivertor pressures (and thus with the divertor pumping). It should be mentioned that the ionization potential for Ne VII is $207.28 \mathrm{eV}$ [23], hence Ne VII emission is predominately from the confined plasma inside the separatrix.

For a given divertor geometry, the impurity exhaust is strongly dependent on the background plasma conditions. Figure 4 shows the time traces of two identical $\mathrm{L}$ mode discharges but with $\mathrm{D}_{2}$ fuelling from different locations: the divertor and the top of the machine, respectively. Neon was introduced from the same position (midplane) in the main chamber using gas puffs for both discharges. In each discharge, the neon was injected during the two steady state phases with different plasma densities. We see that the decay of the neon content in the plasma is strongly dependent on the plasma density or the divertor pressure, but not very sensitive to the gas 


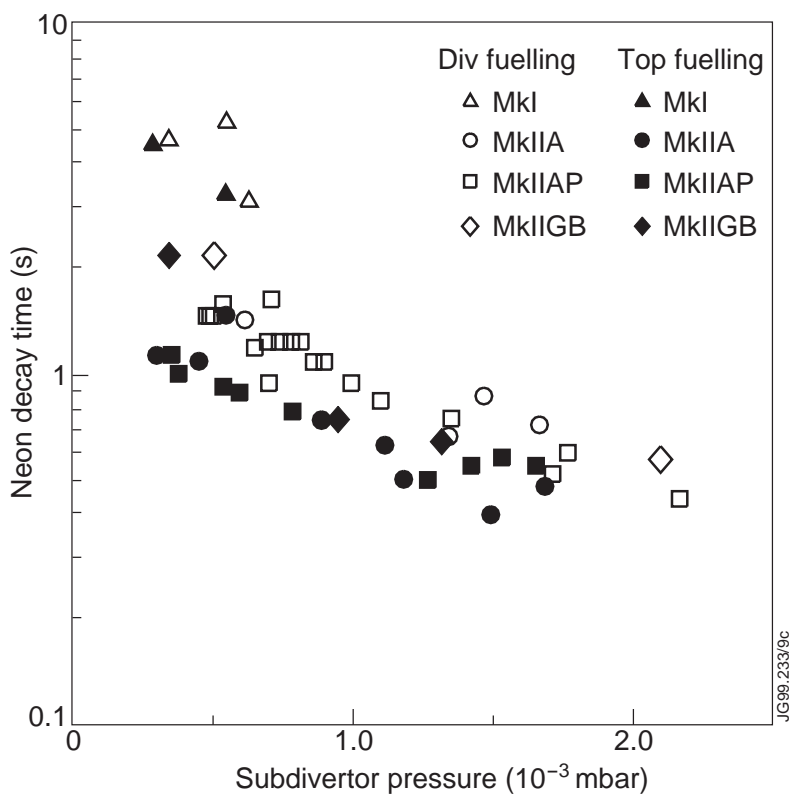

Figure 5. Neon decay time versus subdivertor pressure for the different divertor configurations, with $\mathrm{D}_{2}$ fuelling from top and divertor, respectively.

puff locations. It should be noted that the ion fluxes to the divertor target are nearly identical for the two discharges, as indicated by the ion saturation current measured by the Langmuir probe near the outer strike point. However, the subdivertor pressure is higher in the divertor fuelling case, which is unlikely to be attributed to the recycling neutrals. Therefore, the direct bypass flow of the puffed gas to the subdivertor must contribute to the observed difference. In fact, more gas had to be puffed into the divertor to maintain the same plasma density, compared with the top fuelling case.

Figure 5 shows the $e$-folding decay time of neon versus the subdivertor pressure for the L mode discharges with different divertor configurations. The neon exhaust rates show a clear dependence on subdivertor pressure, and the data from the different divertors produce the same trend. Since the impurity removal rate depends on the partial pressure of the impurities in the subdivertor (next to the divertor cryopump), this would suggest that the neon impurity enrichment (the ratio of the impurity concentration in the subdivertor to the core impurity concentration) is relatively insensitive to the changes in divertor configuration, as will be discussed in Section 2.3. The recent studies for the reduced cost ITER show that the helium concentration upstream is mostly dependent on the DT throughput with a minimum throughput of $200 \mathrm{~Pa} \mathrm{~m}^{3} / \mathrm{s}$ being required to satisfy the constraint on the helium concentration (6\%) [24]. Hence, increasing divertor closure would reduce the requirement for pumping speed for a given throughput (due to increased divertor neutral pressure).

It was expected that injecting deuterium from the top of the machine coupled to the divertor pumping should induce an ion (deuterium) flow in the SOL to enhance the frictional drag on the impurities, thus increasing impurity retention in the divertor, i.e. the so-called 'puff and pump' concept. However, it appears that there is only a small difference in neon decay time between the top and divertor fuelling cases in the Mark II and Mark IIGB divertors (Fig. 5). One possible explanation for this is that the large intrinsic flows, which are present in the SOL, would dominate the flow achievable by $\mathrm{D}_{2}$ fuelling. Measurements from the reciprocating probe located at the top of the machine show a significant plasma flow with Mach number of $0.35-0.6$ in the JET SOL for a variety of plasma conditions [25].

In contrast, an increase in neon exhaust by a factor of three has been observed in DIII-D using top fuelling and simultaneous pumping [26, 27], which was attributed to an externally induced SOL flow, and this puff and pump technique has been found most effective for high- $Z$ impurities, such as argon [28]. In ASDEX Upgrade, no effect or a much smaller one was observed using the puff and pump technique $[29,30]$, similar to JET. These results are presently not fully understood and need further investigation.

\subsection{Impurity enrichment}

Impurity enrichment studies have been performed for helium, neon and argon with different divertor configurations at JET. The core impurity enrichment, i.e.

$\eta_{i m p}=\left(p_{i m p} / 2 p_{D_{2}}\right)_{d i v} /\left(n_{i m p} / n_{e}\right)_{c o r}$

is derived from the ratio of the partial pressure in the subdivertor volume, measured by Penning gauge spectroscopy [31, 32], to the core plasma concentration, determined by charge exchange recombination spectroscopy (CXRS) [33] at $\rho \approx 0.3$. In addition, the impurity enrichment factors at the plasma edge are evaluated on the basis of the impurity concentration measured at $\rho \approx 0.9$. 


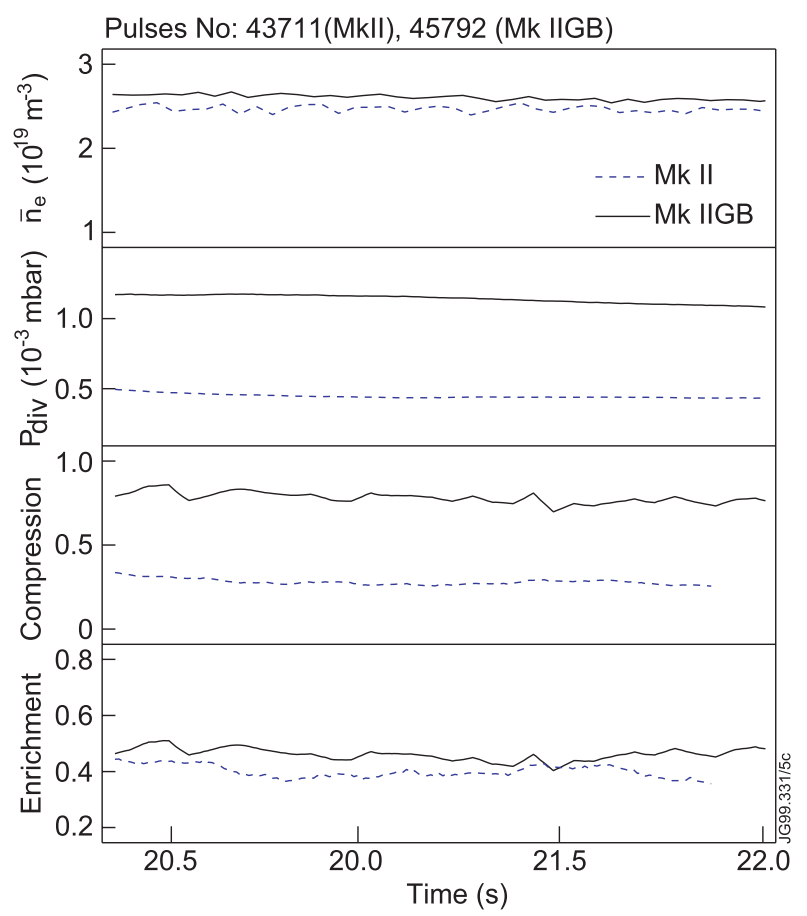

Figure 6. Helium enrichment, helium compression $\left(n_{H e}^{d i v} / n_{H e}^{c o r}\right)$ and subdivertor pressures in two comparable L mode discharges in the Mark II and Mark IIGB divertors.

For L mode discharges the helium enrichment decreases with the subdivertor pressure and also depends upon the strike point position. Preferential enrichment is obtained as the strike point is moved towards the pumping entrance slot [32]. In the case of ELMy $\mathrm{H}$ modes, the enrichment is less sensitive to the strike point position. In going from Mark II to Mark IIGB, helium compression is increased, but the enrichment changes little due to the simultaneous increase in subdivertor neutral pressure. As an example, Fig. 6 shows two L mode vertical target discharges in the Mark II and Mark IIGB divertors with the same neutral beam heating powers (2 MW) and similar plasma densities in order to illustrate the changes in the subdivertor pressure $\left(P_{d i v}\right)$, helium compression, i.e. $n_{\mathrm{He}}^{\mathrm{div}} / n_{\mathrm{He}}^{\mathrm{cor}}$, and helium enrichment. $n_{\mathrm{He}}^{\mathrm{div}}$ is the helium density in the subdivertor derived from Penning gauge measurements assuming room temperature conditions; $n_{\mathrm{He}}^{c o r}$ is the helium density in the core plasma measured by CXRS (at $\rho \approx 0.3$ ).

Detailed comparisons have been made for the enrichment factors between helium and other recycling impurities, i.e. neon and argon in the
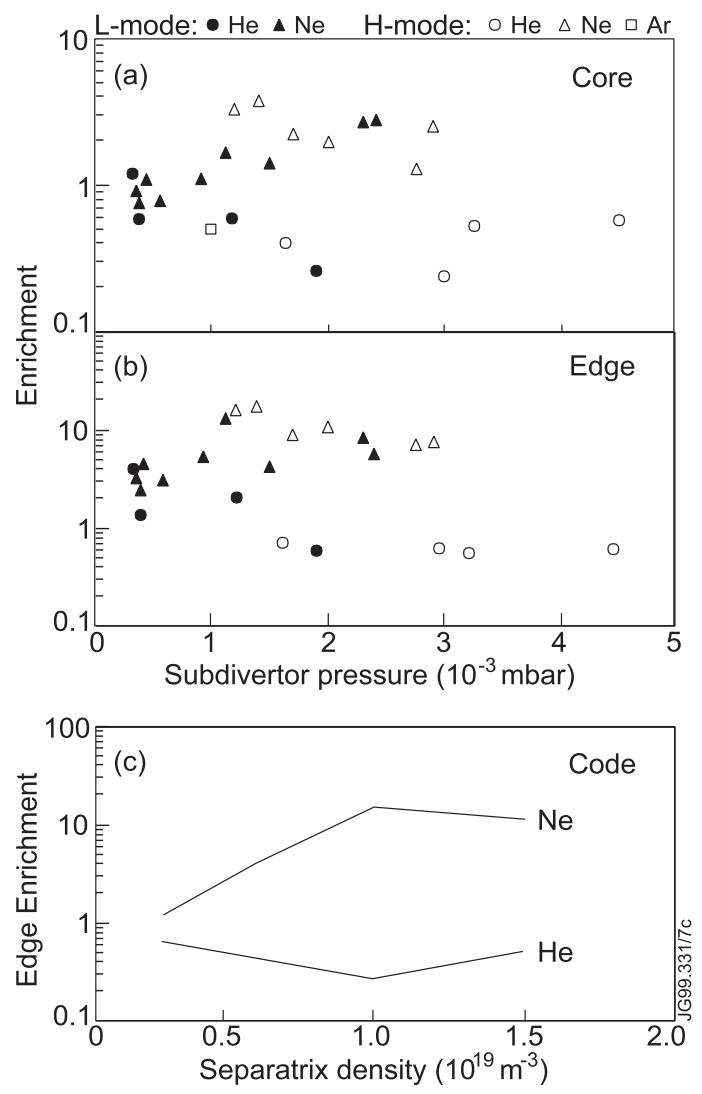

Figure 7. Measured core (a) and edge (b) enrichment factors for helium, neon and argon in the Mark IIGB divertor, together with the EDGE2D results (c).

Mark IIGB divertor. Figure 7 shows the enrichment factors based on densities in the core plasma, as well as the values measured at the edge of the confined plasma (at $\rho \approx 0.9$ ) for helium, neon and argon impurities as a function of the subdivertor pressure in both $\mathrm{L}$ and $\mathrm{H}$ modes discharges. It appears that helium, neon and argon have similar enrichment factors at low subdivertor pressure, or plasma density. The enrichment for neon in $\mathrm{L}$ mode discharges is observed to increase as the subdivertor pressure is increased, in contrast to the helium enrichment, so that higher enrichment factors are achieved for neon than for helium at high subdivertor pressure. In the $\mathrm{H}$ mode discharges, the enrichment factors for both neon and helium exhibit no clear trends. However, increased enrichment for neon can be clearly seen, despite a large scatter. Whilst the enrichment for neon is generally above unity, except at very low subdivertor pressures, a significant de-enrichment $\left(\eta_{\mathrm{He}}<1\right)$ is observed for helium. The reason for this difference [34] is that the helium neutrals have 
a longer mean free path before ionization compared with deuterium or neon. Thus the helium ions tend to be created above the point where the plasma flow towards the divertor target is strong, and the frictional drag towards the plate is therefore weaker. The ion gradient force, directed upstream, tends to be more important, causing more divertor leakage for helium than for other impurities. Nevertheless, in all the cases studied, helium enrichment is above the minimum requirement for ITER, i.e. $\eta_{H e} \geq 0.2$.

We have employed the 2-D fluid EDGE2D/ NIMBUS codes [35] to simulate the enrichment for helium and neon in typical L mode plasmas with the following input parameters: $P_{\text {sol }}=2 \mathrm{MW}$, $n_{\text {sep }}=(0.3-1.5) \times 10^{19} \mathrm{~m}^{-3}, D_{\perp}=0.2 \mathrm{~m}^{2} / \mathrm{s}$ and $\chi_{\perp}^{i, e}=0.5 \mathrm{~m}^{2} / \mathrm{s}$ (in flux space). The intrinsic carbon content is controlled by both physical and chemical sputtering. The chemical sputtering yield is taken from the work of the University of Toronto group [6] with a yield reduction factor of 0.5 (in order to allow for some effect of molecular hydrocarbon fragment suppression at high incidence flux, and for prompt redeposition). Thus the effective sputtering yield is given by $Y_{\text {eff }}=Y_{\text {phys }}+0.5 Y_{\text {chem }}^{\text {Toronto }}$. More details on the impurity source modelling will be described in Section 3.5. As in the experiments, only small quantities of helium and neon are introduced into the SOL so that the background plasma parameters are little changed due to the presence of neon. The calculated enrichment factors, relative to the edge impurity concentration, are shown in Fig. 7(c) as a function of the separatrix density. The code reproduces the observed trends and also the absolute values for both helium and neon. In particular, the calculated results show that neon enrichment increases with separatrix density and rolls over at sufficiently high densities, in contrast to helium enrichment, which is related to the respective ionization mean free paths of helium and neon.

\subsection{Intrinsic impurity behaviour}

The increased divertor closure improves the plasma purity in the L mode discharges, as expected. Figure 8 compares the $Z_{\text {eff }}$ and the radiated power $P_{\text {rad }}$ between Mark II and Mark IIGB divertors for $\mathrm{L}$ mode discharges with the same vertical target configuration and the same additional neutral beam heating $(\sim 2 \mathrm{MW})$. The $Z_{\text {eff }}$ values are derived from the bremsstrahlung emission at $523 \mathrm{~nm}$ and the

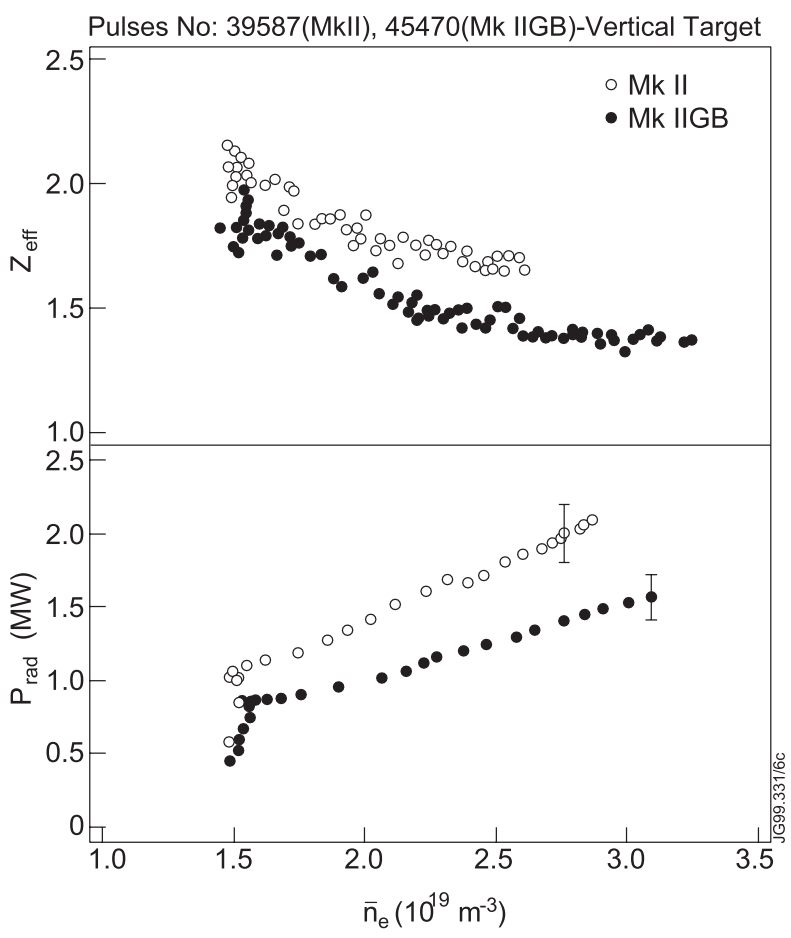

Figure 8. $Z_{\text {eff }}$ and $P_{\text {rad }}$ plotted against plasma line averaged density for $\mathrm{L}$ mode discharges in the Mark II and Mark IIGB divertors.

radiated power is obtained from tomography reconstruction. As can be seen, $Z_{\text {eff }}$ is reduced from Mark II to Mark IIGB. As a result, the radiation is reduced at a given plasma density. Note that the $Z_{\text {eff }}$ measurements are subject to large uncertainties (up to $30 \%$ ). However, the data from the CXRS show similar trends. In addition, the L mode density limit is improved in the Mark IIGB discharge compared with the Mark II case (as will be discussed in Section 3.2). This further confirms the improved plasma purity in the Mark IIGB divertor.

No obvious changes in $Z_{\text {eff }}$ have been observed in the ELMy H modes [21, 36]. Some possible explanations for this are as follows: as the divertor becomes geometrically more closed, ion impact during an ELM can lead to stronger impurity sputtering at the components forming the narrow entrance of the divertor where impurities can more efficiently contaminate the core, compared with the impurities originating at the target plate. In addition, the impurity sources in the Mark II divertor are higher than that in the Mark I divertor, hence offsetting the effect of divertor closure, as will be discussed in the following section. 


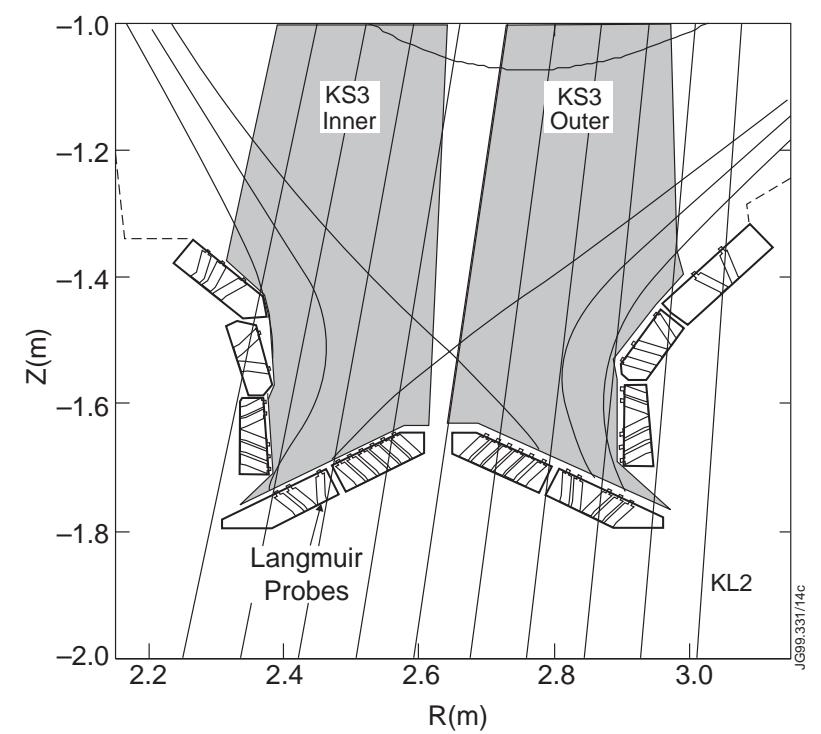

Figure 9. Vertical cross-section of the Mark II divertor showing a typical horizontal target magnetic configuration and diagnostic lines of sight of the KS3 visible spectrometer and the KL2 flux cameras. Also indicated are the fixed Langmuir probe locations.

\section{Effect of divertor surface temperature on impurity production and plasma performance}

\subsection{Divertor carbon source}

Divertor operation at JET leads to strong interaction of the plasma with the carbon divertor target plate with an ion flux density up to $10^{24} \mathrm{~m}^{-2} \mathrm{~s}$ in the strike zones. The hydrogenic and impurity behaviour are routinely monitored in JET with various spectroscopic diagnostics. In particular, a visible spectrometer (KS3) and three flux cameras (KL2) are employed to routinely monitor a large number of low charge state ions, indicating hydrogenic and impurity influxes. The KS3 spectrometer is absolutely calibrated to measure the integrated photon fluxes, such as $\mathrm{D}_{\alpha}(656.1 \mathrm{~nm})$ and C III $(465 \mathrm{~nm})$, from both the inner and the outer divertor. The spatial distributions of bremsstrahlung (at $523.5 \mathrm{~nm}$ ), $\mathrm{D}_{\alpha}(656.1 \mathrm{~nm})$ and C II $(658 \mathrm{~nm})$ across the target plates are obtained from the flux cameras with interference filters. Both the diagnostics view the divertor from the top of the vessel. Figure 9 shows the lines

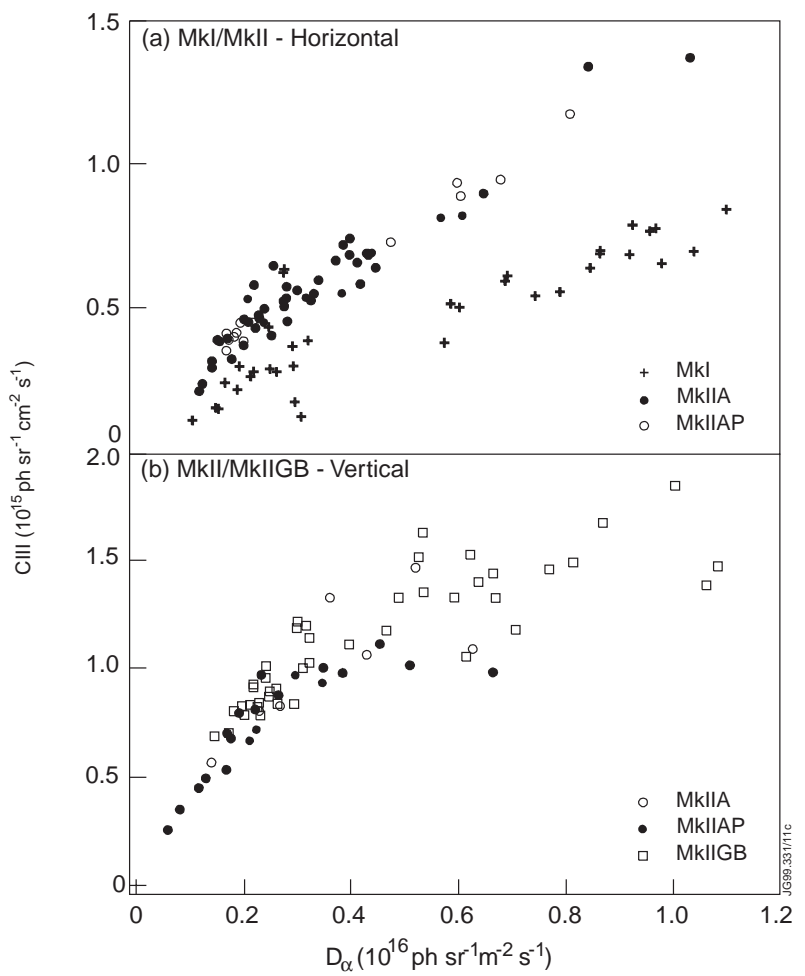

Figure 10. (a) C III emissions from the outer divertor as a function of the $\mathrm{D}_{\alpha}$ photon fluxes in the Mark I, Mark IIA and Mark IIAP divertors with various magnetic configurations to illustrate the changes in the impurity yield between the Mark I and Mark II divertors. (b) A comparison is also made between the Mark II and Mark IIGB divertors.

of sight of the KS3 visible spectrometer and the view of the KL2 flux cameras.

The dominant impurity in JET is carbon [36]. One unexpected result of Mark II divertor operation is that the carbon production yield at the divertor target is increased in the Mark II divertor relative to that in the Mark I. Figure 10(a) shows the average C III photon flux as a function of the $\mathrm{D}_{\alpha}$ intensity from the outer strike zones in the Mark I, Mark IIAP divertors for operation with the horizontal target plates. Both $\mathrm{C}$ III and $\mathrm{D}_{\alpha}$ are measured simultaneously by the KS3 spectrometer. For comparison, Fig. 10(b) shows the impurity source (C III) versus the $\mathrm{D}_{\alpha}$ intensity for the discharges with strike points placed on the vertical targets in the Mark IIA, Mark IIAP and Mark IIGB divertors. Note that the comparison between the Mark I and Mark II divertors is made for horizontal target operation since few discharges were carried out with the vertical target magnetic configuration in the Mark I divertor, 
whilst the vertical target configuration is selected for the Mark II/Mark IIGB comparison due to the fact that no horizontal target operation is possible in the Mark IIGB divertor due to the constraint on the septum. The data are selected from the steady state ELMy $\mathrm{H}$ mode database with neutral beam heating power restricted between 10 and $16 \mathrm{MW}$, plasma current $I_{p}$ varying from 1 to $4.7 \mathrm{MA}$ and the toroidal magnetic field $B_{T}$ varying between 1 and $3.4 \mathrm{~T}$ with a variety of magnetic configurations.

As can be seen, the C III intensity is about a factor of two higher in the Mark II divertor than that in the Mark I divertor for a given $\mathrm{D}_{\alpha}$ flux. The C III and $\mathrm{D}_{\alpha}$ emissions from the inner divertor show similar results. It should be noted that the electron temperature and density at the target plate are very similar for the Mark I and Mark II discharges at the strike points, as measured by the target Langmuir probes. Therefore, the higher $\mathrm{C} I \mathrm{III} / \mathrm{D}_{\alpha}$ ratio suggests an increased impurity production yield at the Mark II divertor target. One explanation proposed for the higher carbon yield in the Mark II divertor is that the chemical sputtering yield is increased resulting from the higher base temperature of the Mark II target plate [17], i.e. 500 K, compared with the $\sim 300 \mathrm{~K}$ of the Mark I tiles, due to changes in the divertor cooling system. It has been observed from ion beam experiments $[6,11]$ that the chemical yields of hydrocarbons, i.e. methane and also heavier hydrocarbons, increase as the temperature rises, and reach a maximum yield around $600 \mathrm{~K}$. As the temperature is further increased, molecular recombination occurs [11], thus reducing the hydrocarbon formation.

In contrast, similar impurity yields have been observed in the Mark II and Mark IIGB divertors, as illustrated in Fig. 10(b). In fact, both the Mark II and Mark IIGB divertor tiles are operated at similar base temperatures. This further supports the hypothesis that the change in the carbon yield between the Mark I and Mark II divertors is related to the change in divertor tile temperature. Additional evidence comes from the specific experiments with reduced wall/divertor temperature performed in the Mark II divertor, which will be described in Section 3.4.

\subsection{L mode density limit}

Another unexpected result in going from the Mark I divertor to the Mark II divertor is that the

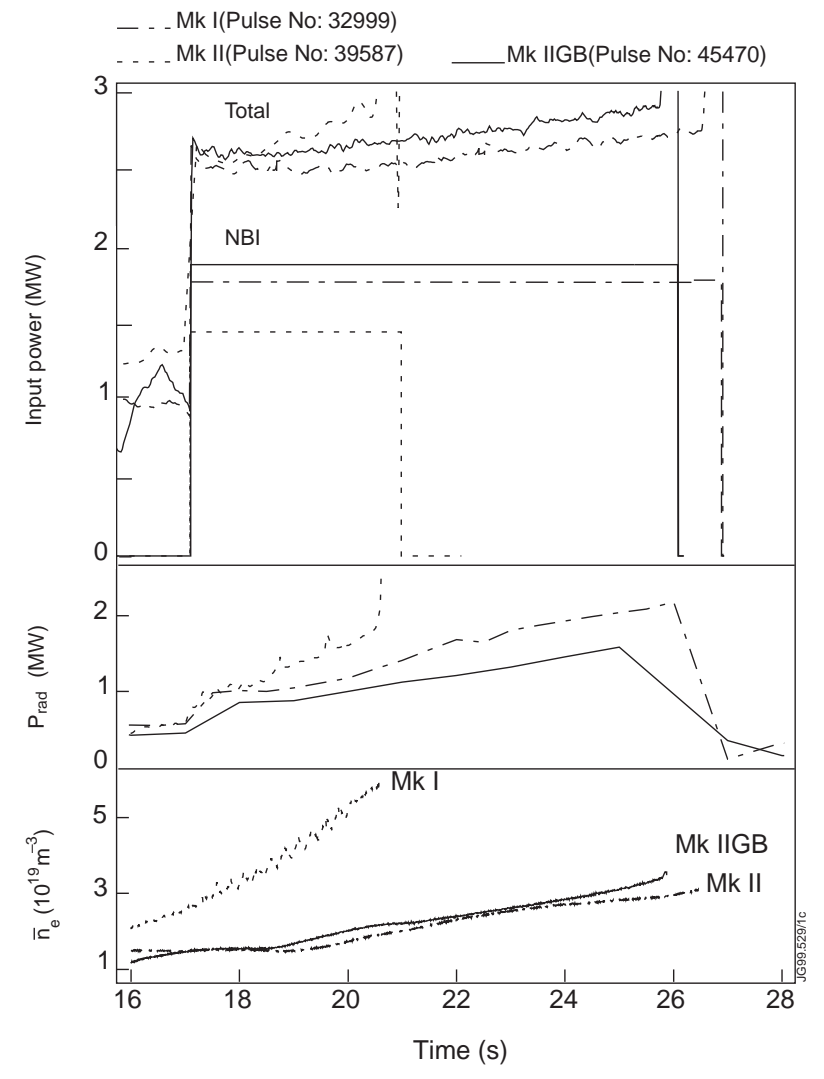

Figure 11. Comparison of the disruptive density limits in vertical target $\mathrm{L}$ mode discharges between the Mark I, Mark II and Mark IIGB divertors.

L mode density limit was reduced by nearly a factor of two [21]. Figure 11 shows the time traces of the L mode discharges carried out in Mark I, Mark II and Mark IIGB divertors with vertical target configurations to illustrate the changes in the disruptive density limit (which occurs at the time when the density traces end) between the different divertors. The discharges have similar neutral beam heating powers. The total input power (including ohmic heating) and the radiated power, obtained from the bolometer measurements, are also shown. In all cases, the density limit is dictated by the formation of a MARFE in the divertor region which moves up to the $\mathrm{X}$ point and eventually to the inner wall just before the disruption. It is obvious that a reduction in the density limit (indicated by the end of the data) in moving from Mark I to Mark II occurs at similar net input powers. From the Mark I and Mark II data alone, it is unclear whether the lower disruptive density limit in the Mark II divertor relative to that of the Mark I divertor is due to increased intrinsic impurity production or due to the increased closure. This is, 


\section{H.Y. Guo et al.}

however, clarified by the result from the Mark IIGB divertor. The density limit in the Mark IIGB divertor was not further reduced in going from Mark II to Mark IIGB. In contrast, it was even slightly increased (about 15\%), as a result of improved plasma purity, as shown in Fig. 8, compared with that in the Mark II divertor.

Additional evidence comes from the results obtained from the specific experiments with reduced divertor tile temperatures carried out with the Mark II divertor. It was found that the density limit was increased with reduced tile temperature, as will be further discussed in Section 3.4. This further supports the idea that the lower density limit in the Mark II divertor is due to increased intrinsic impurity production as opposed to the increased closure. As for the detailed physical mechanism, we can only suppose that the MARFE is more easily destabilized by the increased local carbon concentration in the divertor.

It should be mentioned that in the case of horizontal target operation, an early onset of detachment was observed at the corner of the inner divertor in going from Mark I to Mark II, in contrast to the vertical target case where detachment begins at the separatrix $[37,38]$. This has been reproduced by B2Eirene simulations [39] which show that a cold and dense plasma is present at the inner divertor corner region, thus promoting volume recombination.

\subsection{Edge $Z_{\text {eff }}$ and loss power in the hot ion $H$ mode regime}

For the low recycling hot ion $\mathrm{H}$ mode regime, the higher impurity yield at the divertor target plate manifests itself as an increase in $Z_{\text {eff }}$ at the edge, upstream from the target, due to poor divertor screening for the impurities for this particular regime, as will be further discussed in Section 3.5. The significance of the edge $Z_{\text {eff }}$ for the hot ion $\mathrm{H}$ modes is that the loss power, $P_{\text {loss }}$, has been observed to scale as $n_{\text {edge }}^{2} Z_{\text {eff, edge }}[17,40]$, as predicted by an empirical neoclassical model [41, 42]. This results in a significant increase in the loss power in the Mark II divertor relative to that in the Mark I divertor, thus affecting the fusion performance. To illustrate this, Fig. 12 shows the edge $Z_{\text {eff }}$ measured by CXRS at $R=3.75 \mathrm{~m}(\rho \approx 0.9)$ and the loss power obtained from the TRANSP analysis as a function of the line averaged density for two comparable hot ion $\mathrm{H}$ mode discharges performed in Mark I (pulse 33643) and Mark II (pulse 40346), respectively. The

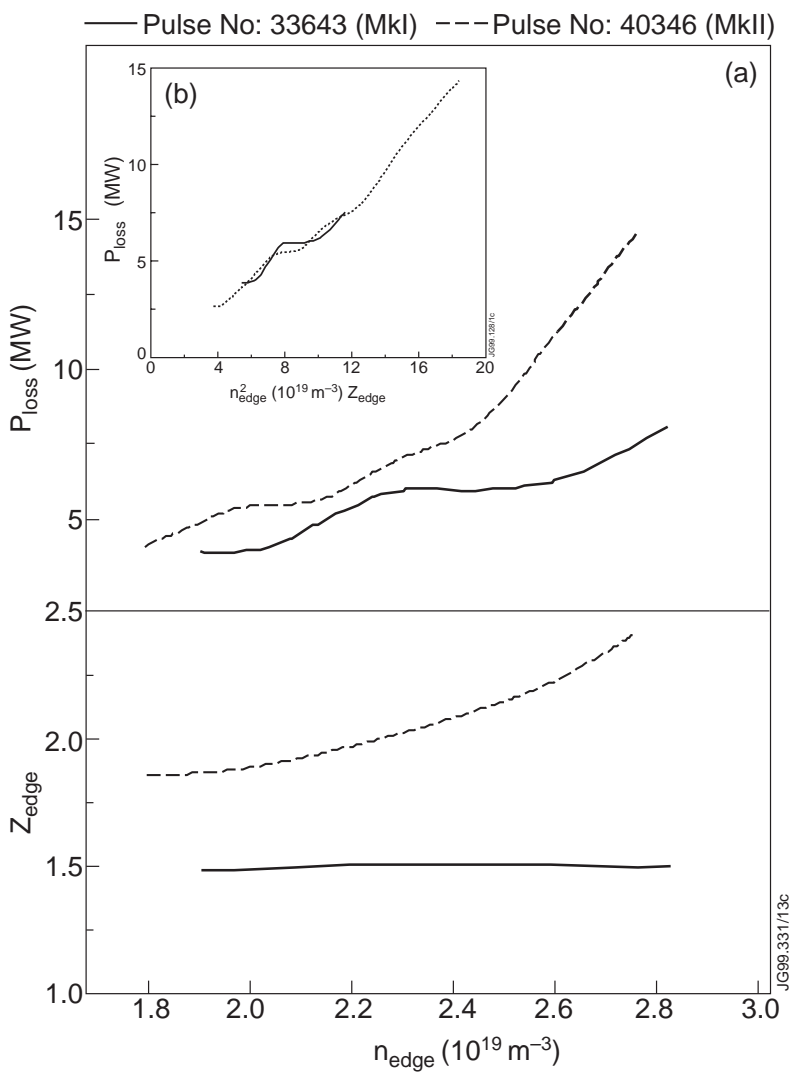

Figure 12. Comparison of $Z_{\text {eff }}$ at the edge and loss power for hot ion $\mathrm{H}$ mode discharges in the Mark I and Mark II divertors. In the inset is shown the loss power scaling: $P_{\text {loss }}$ versus $n_{\text {edge }}^{2} Z_{\text {eff, edge }}$.

two discharges have the same horizontal target magnetic configuration at $3.8 \mathrm{MA} / 3.4 \mathrm{~T}$ with full power neutral beam heating $(\sim 20 \mathrm{MW})$. As can be seen, $Z_{\text {eff }}$ at the edge, at a given plasma density, is significantly higher for the discharge in the Mark II divertor. As a result, the loss power is increased in the Mark II divertor compared with the Mark I divertor and is consistent with the neoclassical scaling, i.e. $P_{\text {loss }} \propto n_{\text {edge }}^{2} Z_{\text {eff,edge }}$, as shown in the inset of Fig. 12.

\subsection{Dependence on divertor target temperature}

To investigate the effect of the target surface temperature on chemical sputtering, a series of dedicated experiments was carried out at the end of the Mark II campaign by reducing the wall temperature from 325 to $150^{\circ} \mathrm{C}$, as measured by the thermocouples. Consequently, the divertor tile base temperature was reduced from $\sim 220$ to $\sim 120^{\circ} \mathrm{C}$ through radiative 


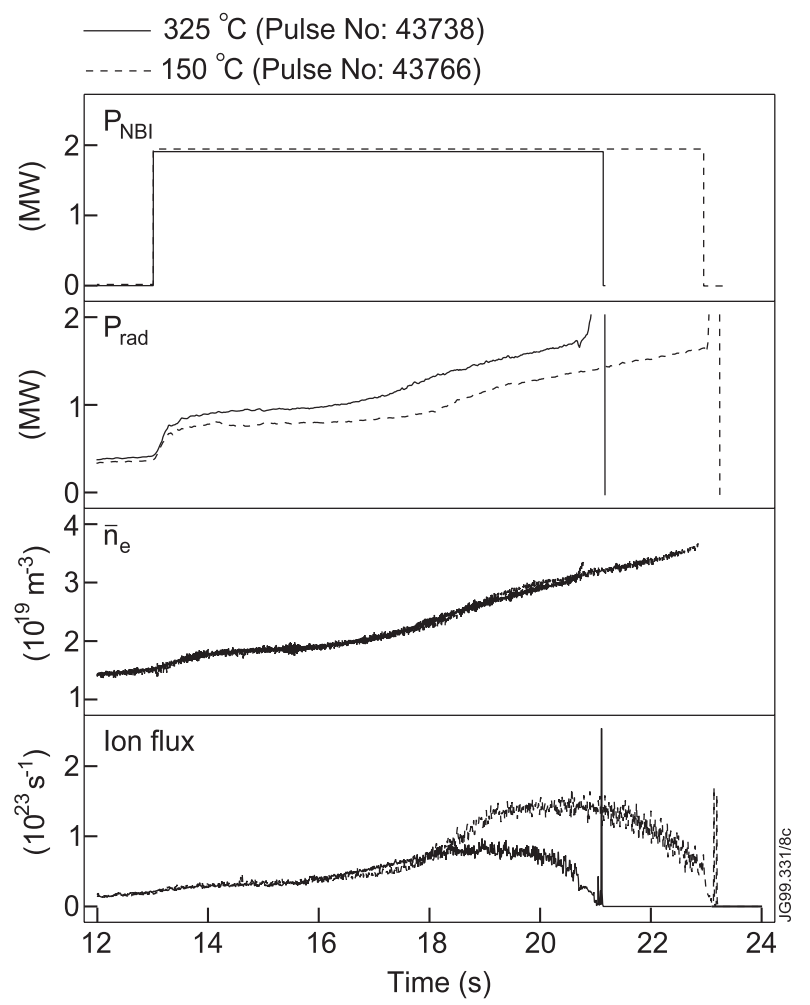

Figure 13. Global behaviour of two L mode discharges carried out before and after the wall temperature reduction.

cooling. Fig. 13 shows the behaviour of a pair of comparable L mode discharges carried out before and after the temperature reduction. The two discharges have the same neutral beam heating (2 MW) and the same magnetic configuration and target orientation (vertical). The plasma line averaged density is continually increased by deuterium gas fuelling until the density limit occurs. As can be seen, for the discharge with lower wall/target temperature both $Z_{\text {eff }}$ (not shown) and the radiation are reduced. Detachment is also delayed compared with the discharge before temperature reduction, as indicated by the total ion fluxes to the outer target plate obtained from the fixed Langmuir probes. Consequently, the discharge with the lower wall temperature proceeds further and reaches a higher density before the disruption, with the density limit increased by $\sim 20 \%$ with respect to the higher temperature case.

The detailed change in the impurity sources for the above two discharges is illustrated in Fig. 14 where the CD band emissions from both the inner and outer targets are plotted, together with the C III emission measured along a horizontal chord through the centre of the plasma, as well as the core

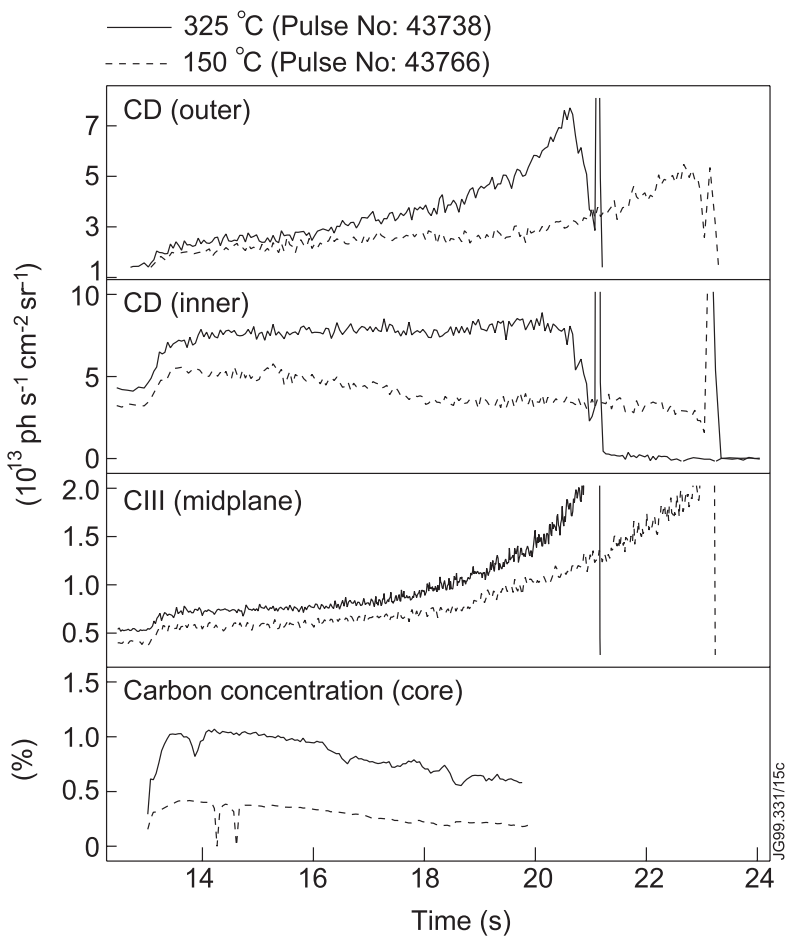

Figure 14. Comparison of the impurity sources from the divertor target and the wall in discharges at different wall/target temperatures. The core carbon concentration is also shown.

carbon concentration, measured by the CXRS diagnostic. At reduced wall/target temperature, the impurity sources at both the inner and outer divertor target plates are reduced, especially at the inner target, as indicated by the CD band emission, where the electron temperature is lower and chemical sputtering is important. The wall source is also reduced, as indicated by the midplane C III intensity. The core carbon concentration is hence reduced in the discharge with the lower wall temperature.

Discharges with the horizontal target magnetic equilibrium show a similar reduction in the wall and divertor carbon sources at the lower vessel wall/divertor target temperatures, resulting in a decrease in the core carbon concentration and an improvement in the disruptive density limit, as observed in the vertical case. Figure 15 shows the spatial distribution of $\mathrm{D}_{\alpha}$ and $\mathrm{C}$ II intensities across the inner and outer targets for two L mode discharges at the horizontal target before and after the temperature reduction. Both discharges have $2 \mathrm{MW}$ neutral beam heating. The profiles are taken at the time when the plasma densities are the same and the particle fluxes at the target plate are also similar, as 


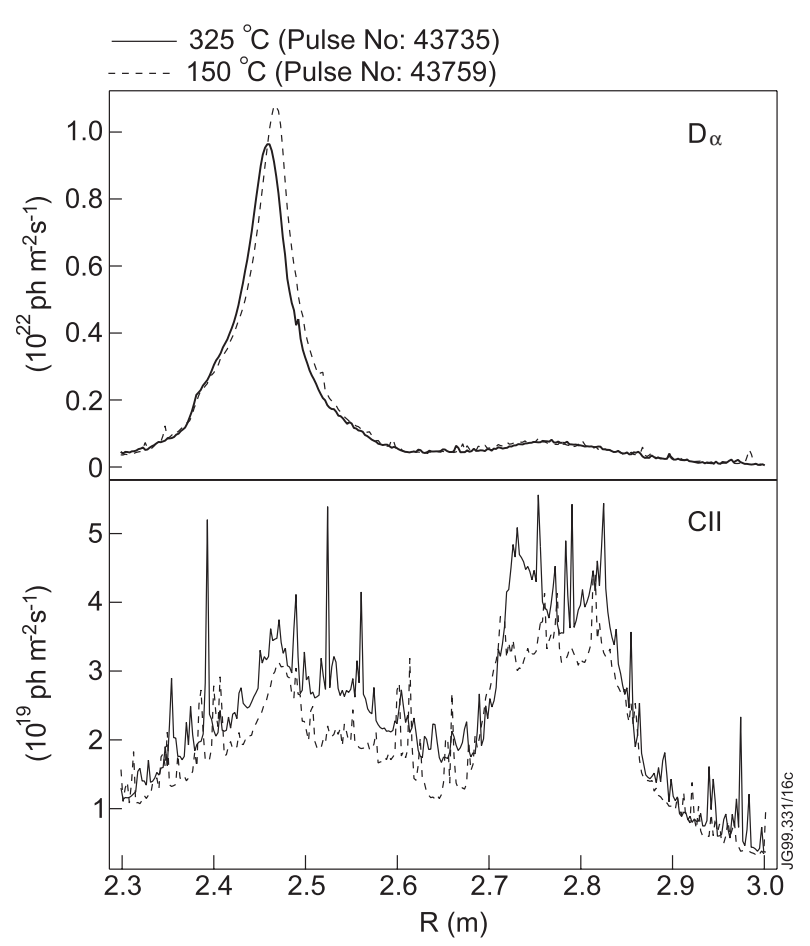

Figure 15. $\mathrm{D}_{\alpha}$ and $\mathrm{C}$ II photon fluxes along the divertor target for two horizontal target $\mathrm{L}$ mode discharges with different vessel wall and divertor target temperatures.

indicated by the $\mathrm{D}_{\alpha}$ emission. It is evident that the C II photon fluxes are reduced by up to $30 \%$ for the discharge at the lower target temperature, i.e. $\sim 120^{\circ} \mathrm{C}$, compared with the discharge with the target temperature at $\sim 220^{\circ} \mathrm{C}$, as predicted by the curves of yield versus temperature from Ref. [6].

In summary, in the discharges at the reduced vessel wall/divertor target temperatures, the carbon sources from both the wall and the target plate were reduced, hence resulting in a reduction in the core carbon concentration. In addition, the L mode density limit was increased (by 20\%). Unfortunately, it was only possible to carry out one hot ion discharge at the reduced wall temperature due to a subsequent water leak of the cooling system. This discharge produced a higher neutron yield than the reference discharge carried out before the wall temperature was reduced, but further experiments are required to confirm this observation. All of the effects seen here are consistent with the experimental results from the Mark I, Mark II and Mark II/GB divertors, as discussed in previous sections (Sections 3.1-3.3). In contrast to expectations (based on early JET operation at $100^{\circ} \mathrm{C}$ ), there was no difficulty in recovering from disruptions at the $150^{\circ} \mathrm{C}$ wall temperature.

\subsection{Modelling}

\subsubsection{Divertor screening}

In contrast to physical sputtering, chemically produced impurities have lower energy, of the order of $\sim 0.5 \mathrm{eV}$, as expected from simple molecular breakup of methane [43]. These low energy neutrals are ionized close to the divertor target where the plasma flow is strong, thus leading to prompt local redeposition [44]. In addition, hydrocarbon neutral fragments produced during the break-up processes could also be deposited across the magnetic field onto the target plates near their point of origin.

In an attempt to better understand the effect of divertor screening for the impurities and to assess the different contributions of the physical and chemical sources to the core contamination, we have carried out detailed modelling using the EDGE2D/NIMBUS [35] and DIVIMP [45, 46] codes for the plasmas in different recycling regimes. DIVIMP is a Monte Carlo impurity transport code, coupled to the 2-D NIMBUS Monte Carlo neutral code. A 2-D background plasma for DIVIMP is either generated using 'onion skin' models, based on the measurements of Langmuir probes at the target plates to define boundary conditions, or taken from the EDGE2D solutions. In particular, we have selected the following cases for detailed modelling:

(a) Low recycling, hot ion $\mathrm{H}$ mode: pulse 40346, horizontal target, $I_{p}=3.8 \mathrm{MA}, B_{T}=3.4 \mathrm{~T}$.

(b) High recycling, ELMy $\mathrm{H}$ mode: pulse 40000, horizontal target, $I_{p}=2.5 \mathrm{MA}, B_{T}=2.5 \mathrm{~T}$.

Carbon sources at the wall and the divertor target plates are computed assuming both physical and chemical sputtering. The physically sputtered impurities are assumed to have a Thompson velocity distribution, whilst the chemically sputtered atoms are given an energy of $0.5 \mathrm{eV}$. The current available chemical sputtering data exhibit large uncertainties [6-13] and the atomic data for various hydrocarbon decomposition processes are poorly known. The actual break-up of $\mathrm{CD}_{4}$ and other hydrocarbon products has not yet been modelled by the EDGE2D/NIMBUS code. In this simulation, we have used the data from the Toronto group [6], which were measured at low incident ion beam fluxes $\left(10^{18} \mathrm{D}^{+} \mathrm{m}^{-2} \mathrm{~s}^{-1}\right)$. A yield reduction factor, $\alpha_{\text {chem }}$, is used to allow for any flux dependence or prompt redeposition, with the effective chemical sputtering yield given by $\alpha_{\text {chem }} Y_{\text {chem }}^{\text {Toronto }}$. 
Table 1. Input parameters used in the EDGE2D simulation for pulses 40346 (low recycling) and 40000 (high recycling)

\begin{tabular}{lccccccc}
\hline Pulse & $\begin{array}{c}P_{S O L} \\
(\mathrm{MW})\end{array}$ & $\begin{array}{c}n_{s} \\
\left(10^{19} \mathrm{~m}^{-3}\right)\end{array}$ & $\begin{array}{c}D_{\perp} \\
\left(\mathrm{m}^{2} / \mathrm{s}\right)\end{array}$ & $\begin{array}{c}\chi_{\perp}^{i} \\
\left(\mathrm{~m}^{2} / \mathrm{s}\right)\end{array}$ & $\begin{array}{c}\chi_{\perp}^{e} \\
\left(\mathrm{~m}^{2} / \mathrm{s}\right)\end{array}$ & $\begin{array}{c}V_{\text {pinch }} \\
(\mathrm{m} / \mathrm{s})\end{array}$ & $\alpha_{\text {chem }}$ \\
\hline 40346 & 5.5 & 0.5 & 0.1 & 0.4 & 0.2 & 6 & 0.5 \\
40000 & 4 & 1 & 0.1 & 0.4 & 0.2 & 4.5 & 0.3 \\
\hline
\end{tabular}

The modelling has concentrated on the ELM-free phase of the discharges with the input parameters to the EDGE2D code listed in Table 1. The crossfield transport coefficients are similar to those used in the previous simulations for ELM-free hot ion $H$ modes $[17,47]$. In the case of the high recycling ELMy $\mathrm{H}$ mode, the inward pinch velocity is slightly reduced to match the ion saturation current, $J_{\text {sat }}$, and electron temperature, $T_{e}$, profiles measured by the Langmuir probes at the divertor target plates. In addition, the parallel transport is modelled with a 21 moment approach for all species [48].

The power flux through the separatrix, $P_{S O L}$, is determined from the total absorbed power from the neutral beam heating, subtracting $d W / d t$ and the radiation inside the core, taking into account the beam shine through loss, CX losses and loss to rotation, as well as the power stored in the fast ion channel, as obtained from the TRANSP analysis. In the simulation, $P_{S O L}$ is then split into the ion channel, $P_{i}$, and the electron channel, $P_{e}$, in such a way that the target parameters could be best matched. For the modelling of the low recycling hot ion regime, little power is needed to be added to the electron channel, i.e. $P_{i}=5.0 \mathrm{MW}, P_{e}=0.1 \mathrm{MW}$, to reproduce the electron temperature at the target, in contrast to the high recycling case where $P_{i}=3.0 \mathrm{MW}$, $P_{e}=1.0 \mathrm{MW}$ had to be assumed.

Figure 16 compares the experimental $J_{\text {sat }}$ and $T_{e}$ profiles at the outer target plate and the modelled results for the two cases. Comparisons for the inner target plate are not considered as the experimental $J_{\text {sat }}$ and $J_{e}$ profiles are not well defined. As can be seen, the ion flux to the target for the high recycling case (pulse 40000) is significantly higher than that in the low recycling hot ion case (pulse 40346), but the electron temperature is about a factor of two lower. Figure 17 shows the poloidal distribution of the C II photon fluxes along the divertor target for the two discharges, together with the modelled results. To reproduce the measured carbon target profiles, we have to use slightly different yield reduction factors

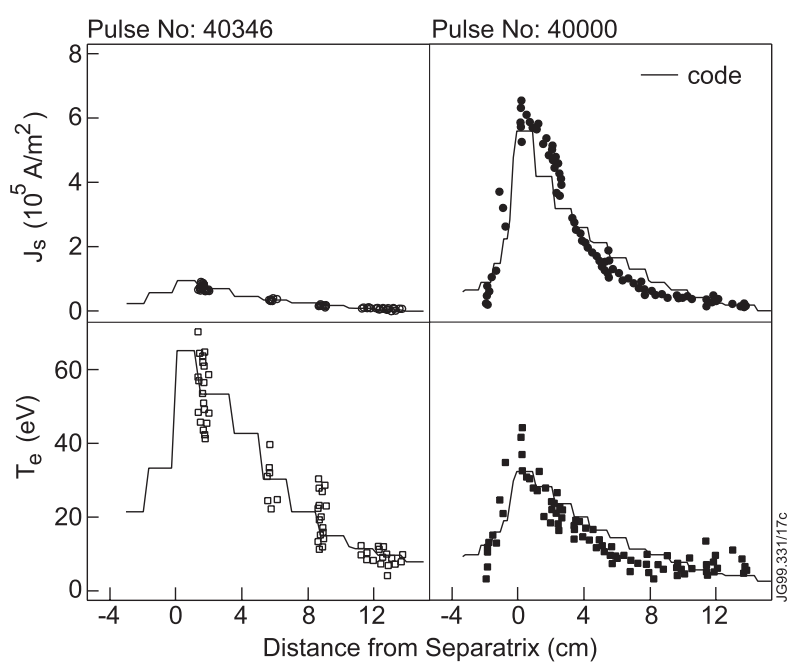

Figure 16. Comparison of experimental $J_{\text {sat }}$ and $T_{e}$ profiles along the outer target plate and the code predictions for the low recycling hot ion $\mathrm{H}$ mode (pulse 40346) and the high recycling ELMy $\mathrm{H}$ mode (pulse 40000) discharges.

for the two cases: $\alpha_{\text {chem }}=0.5$ for the low recycling (hence low ion flux) case and $\alpha_{\text {chem }}=0.3$ for the high recycling case. This may be suggestive of a flux dependence of the chemical sputtering yield of the form $Y_{\text {chem }} \propto \Gamma^{-0.2}$, taking into account the energy dependence of the yield.

To obtain detailed impurity source distributions and the relative contribution of physical and chemical sputtering to the core contamination, we have employed the DIVIMP Monte Carlo code as a postprocessor of the EDGE2D code. In this case, the 2-D solution of the EDGE2D code is directly coupled to DIVIMP as background plasma. The impurity neutrals are launched using both physical and chemical sputtering resulting from the impact of ions and atoms using the same sputtering data as in the EDGE2D simulation. The particles are then followed through each ionization state until they redeposit on the target plates or on the wall. Figure 18 shows 


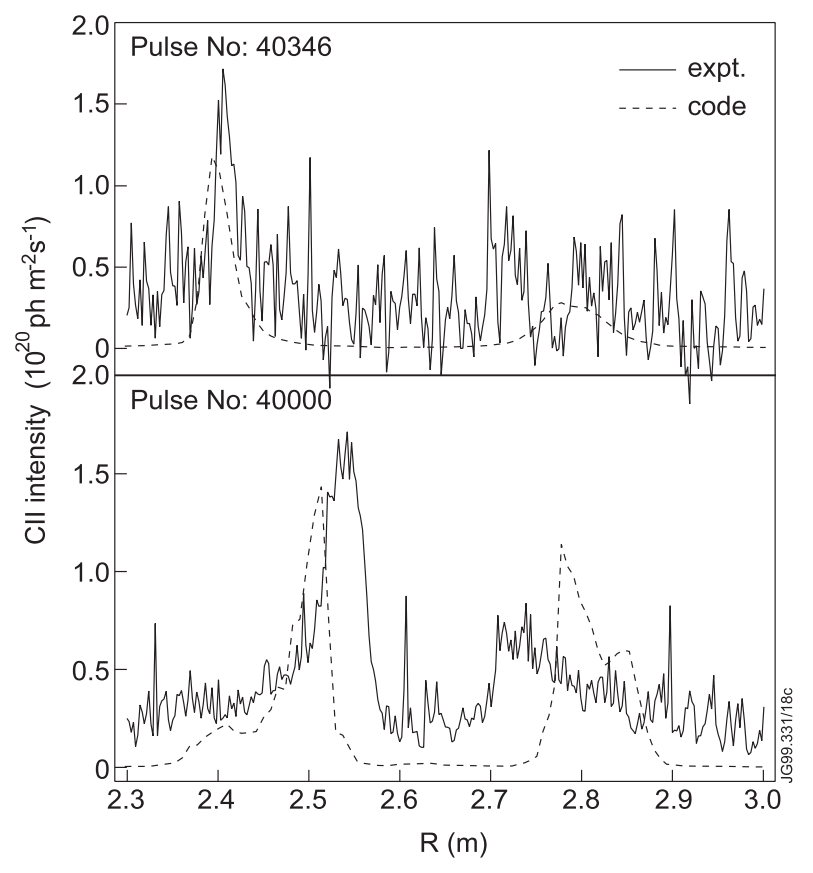

Figure 17. C II photon fluxes along the divertor target, together with the calculated results, for pulses 40346 and 40000.

the source distribution of carbon produced by the different sputtering processes, i.e. physical, chemical and self-sputtering, together with the leakage (the amount of carbon that reaches the confined plasma) for different locations for the higher recycling case (pulse 40000). As can be seen, the target sources dominate and the total carbon source is largest at the outer target. It appears, however, that the impurities produced at the target plates are well screened, while the wall source makes a significant contribution to core contamination. This is consistent with the experimental results from the methane puffing experiment carried out in the Mark II divertor [49]. It was observed that $\mathrm{CD}_{4}$ puffing from the main chamber with $3 \times 10^{21}$ molecules $/ \mathrm{s}$ increased core carbon density by $40 \%$ while the same source injected in the divertor increased core carbon by only about $15 \%$. Previous JET results also showed a strong contribution from the wall source [16].

In addition, we see that chemical sputtering makes a significant contribution to the total impurity source. However, the chemically produced carbon is much better screened compared with the physically sputtered source, as expected. In particular, note that the chemically sputtered impurities at the target plates are almost completely screened and make little contribution to the core carbon. a) Total source (19658 Particles)

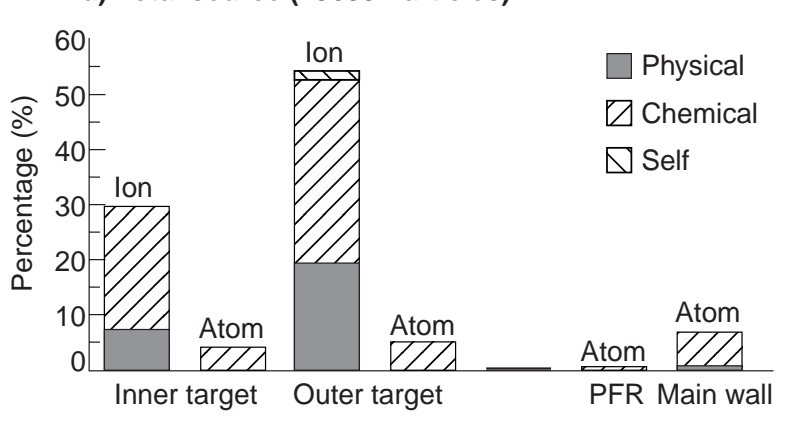

b) Total leakage (327.9 Particles or $1.67 \%$ )

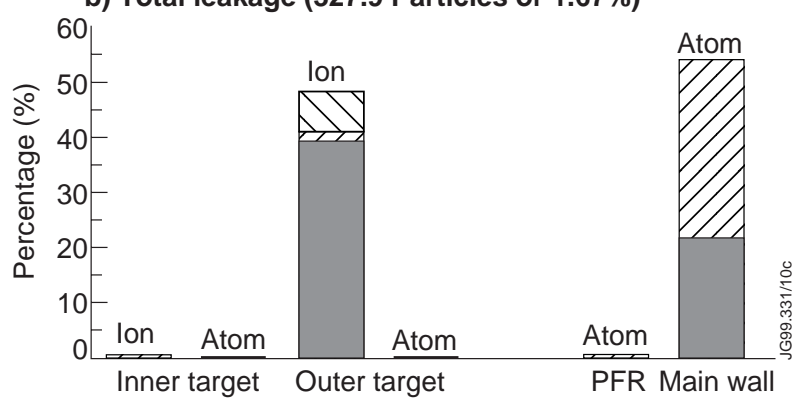

Figure 18. Source and leakage summary calculated by the EDGE2D/DIVIMP codes for the high recycling case (pulse 40000): (a) carbon source distribution due to physical and chemical processes via ion/atom impact at the inner and outer targets, the private flux region (PFR) and the main chamber wall; (b) leakage (or penetration efficiency) versus location.

For comparison, Fig. 19 shows the EDGE2D/ DIVIMP results for the low recycling case (pulse 40346). As can be seen, the total carbon source is largest at the outer and inner divertors. However, in comparison to the high recycling case, the screening for the impurities produced in the divertor is not as good. The code predicts that the divertor source contributes significantly to the core carbon content.

In short, the results from the EDGE2D and DIVIMP modelling show the screening for the divertor impurities is strongly dependent on the plasma conditions. In particular, the codes predict that changes in divertor carbon source affect significantly the plasma purity for the low recycling regime but not for the high recycling regime.

\subsubsection{Predictions for Mark I and Mark II divertors}

To assess quantitatively the changes in chemical sputtering yields in the Mark I and Mark II divertors and the consequence of this for the plasma purity for the low recycling hot ion regime, we selected two of the best hot ion $\mathrm{H}$ modes in Mark I and Mark II, 
Table 2. Comparison of experimental $\mathrm{D}_{\alpha}$ and C III emissions, as well as $Z_{\text {eff, edge }}$, together with the code predictions for pulses 33643 (Mark I) and 40346 (Mark II)

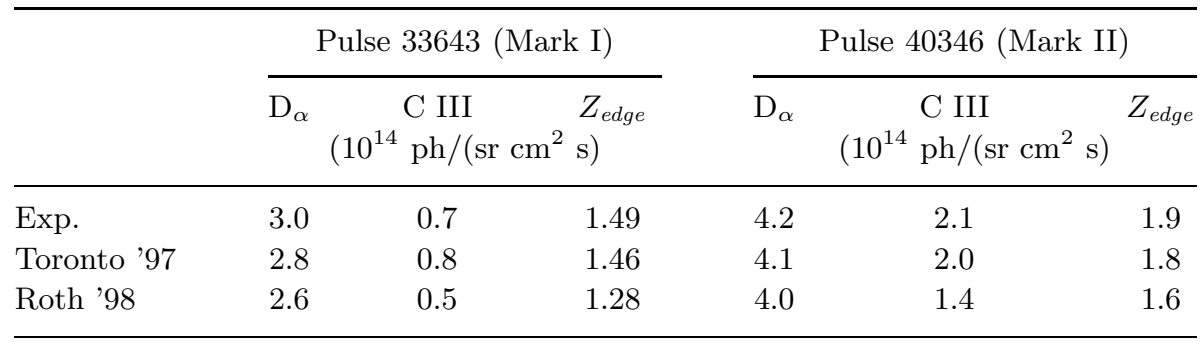

a) Total source (3580 particles)

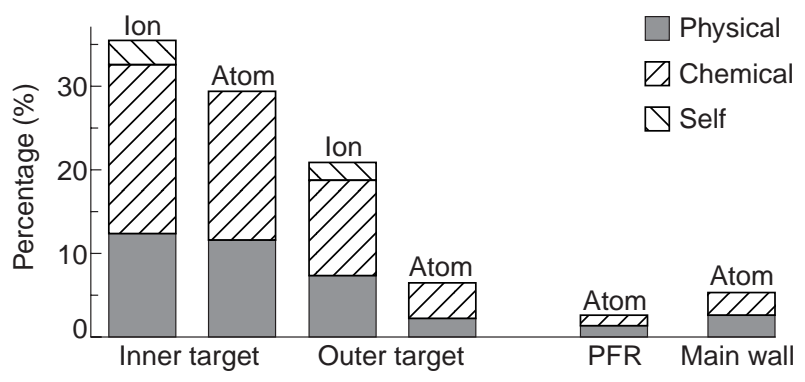

b) Total leakage (653 particles)

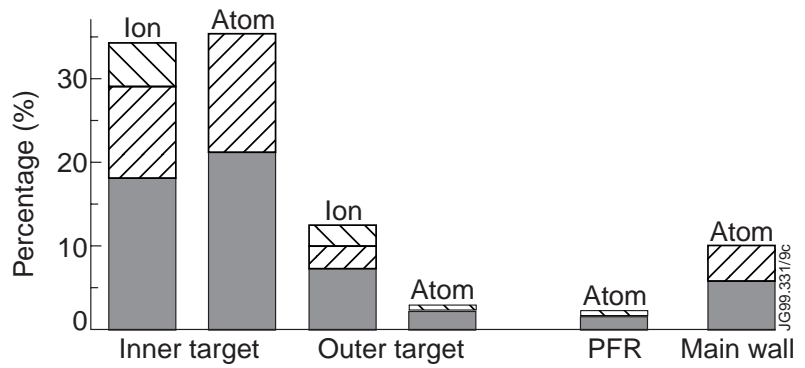

Figure 19. EDGE2D/DIVIMP calculation for the low recycling case (pulse 40346) showing (a) source distribution and (b) leakage versus location.

pulses 33643 (Mark I) and 40346 (Mark II). Similar simulations were performed for the Mark I discharge, as for the Mark II hot ion discharge, with the same cross-transport coefficients (Table 1), but with different target plate temperatures. In the simulation of the Mark II discharge presented in Section 3.5.1, the average surface temperature for the plasma wetted area was taken to be $400^{\circ} \mathrm{C}$, which is consistent with the infrared temperature measurements, with a temperature of $300^{\circ} \mathrm{C}$ for other areas of the machine, whilst in the case of Mark I, the temperature rise of the wetted area of the divertor target was also taken to be $100^{\circ} \mathrm{C}$, but with a tile base temperature of $30^{\circ} \mathrm{C}$ only. For the Mark I discharge, the power flux through the separatrix, $P_{S O L}$, is about $5 \mathrm{MW}$, as determined from the TRANSP analysis, which is mainly put in the ion channel with only $0.1 \mathrm{MW}$ in the electron channel as for the Mark II case. In addition, a separatrix density of $5.0 \times 10^{18} \mathrm{~m}^{-3}$ is specified as input to the code to match the plasma parameters at the divertor target plate.

Table 2 compares the measured $\mathrm{C}$ III and $\mathrm{D}_{\alpha}$ emissions from the outer divertor with the EDGE2D results for pulse 33643 and pulse 40346. Both C III and $\mathrm{D}_{\alpha}$ emissions are reproduced by the code using the Toronto chemical sputtering yield with a yield reduction factor of 0.5 . In particular, the measured photon ratio $\mathrm{C} I I I / \mathrm{D}_{\alpha}$ is about a factor of two higher in pulse 40346 (Mark II) relative to pulse 33643 (Mark I), and is reproduced by the code taking into account the change in the temperatures between the Mark I and Mark II divertor targets. A similar calculation using the newly revised chemical sputtering formula of Roth et al. [9] also predicts the change in the chemical sputtering yield between Mark I and Mark II, as shown in Table 2.

Figure 20 shows the EDGE2D predictions of $Z_{\text {eff,edge }}$ as a function of the separatrix density $n_{s}$ for Mark I and Mark II with $P_{S O L}=5.5 \mathrm{MW}$. The simulations, which are calibrated against the hot ion $\mathrm{H}$ mode discharges described above, show that at low density the plasma is in the low recycling regime where the screening is poor and $Z_{\text {eff }}$ at the edge increases with the separatrix density. In this particular regime, the edge $Z_{\text {eff }}$, at a given separatrix density, is significantly higher in Mark II due to increased divertor chemical sources. As $n_{s}$ increases sufficiently the plasma enters the high recycling regime where screening for impurities is strong and $Z_{\text {eff, edge }}$ shows little change between Mark I and Mark II, in agreement with the experimental observations. 


\section{H.Y. Guo et al.}

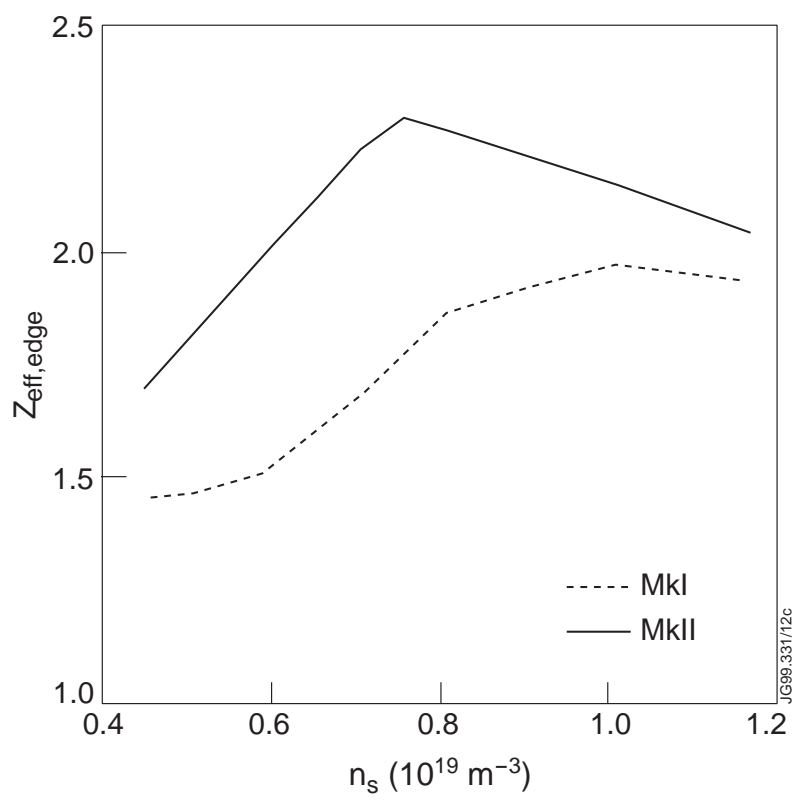

Figure 20. $Z_{\text {eff, edge }}$ as a function of outer midplane separatrix density in the Mark I and Mark II divertors, predicted by the EDGE2D simulation in which only the divertor geometry is varied, with $P_{S O L}=5.5 \mathrm{MW}$.

\section{Summary and conclusions}

Increasing the divertor closure in JET has led to a significant increase in the neutral pressure in the subdivertor, hence improving deuterium pumping. The exhaust for recycling impurities has also been improved with increased divertor closure, from Mark I to Mark II to Mark IIGB, and shows a strong correlation with the subdivertor pressure or particle throughput. Experiments using simultaneous deuterium gas injection into the upstream SOL and divertor pumping show a small effect of induced SOL flow on the impurity exhaust, in contrast to the results from the 'puff and pump' experiment on DIII$\mathrm{D}[26-28]$, and this may be due to the large intrinsic SOL flows that are present in JET.

Helium enrichment studies have been performed under both L and ELMy H mode conditions in the Mark II and Mark IIGB divertors. In going from MARK II to MARK IIGB, the helium compression is increased in step with $\mathrm{D}_{2}$ compression. As a result, the enrichment shows little change between the two divertors. Helium enrichment decreases with plasma density or subdivertor pressure in the $\mathrm{L}$ mode discharges, but remains similar in the ELMy $\mathrm{H}$ mode discharges. Helium shows a significant de-enrichment with $\eta_{H e}<1$. Nevertheless, in all the cases studied, helium enrichment is above the minimum requirement for ITER $\left(\eta_{H e} \geq 0.2\right)$. Neon, as well as argon, has enrichment factors similar to helium at low subdivertor pressure. However, neon enrichment is significantly improved at elevated pressures in both $\mathrm{L}$ modes and ELMy $\mathrm{H}$ modes. In particular, in the $\mathrm{L}$ mode discharges, neon enrichment increases with subdivertor pressure, contrary to the helium case. This effect is related to the respective ionization mean free paths, and is reproduced by the EDGE2D/NIMBUS codes.

With respect to the intrinsic impurity behaviour, the divertor closure manifests itself as a decrease in $Z_{\text {eff }}$ in $\mathrm{L}$ mode discharges, as observed in the Mark II and Mark IIGB divertors. The improved plasma purity leads to an improvement in the density limit (by $\sim 15 \%$ ) in the Mark IIGB divertor. In contrast, no obvious changes in $Z_{\text {eff }}$ have been observed in the ELMy H mode discharges [21,36], presumably due to stronger impurity sputtering at the entrance baffles of the more closed divertor geometry, thus offsetting the effect of the divertor closure.

In contrast to expectations, the divertor carbon source was significantly increased in the Mark II and Mark IIGB divertors, compared with that in their Mark I predecessor. As a result, the disruptive density limit in the L mode discharges was dramatically reduced in the Mark II and Mark IIGB divertors, by nearly a factor of two compared with that in the Mark I divertor. The increased carbon source is attributed to the enhanced chemical sputtering at the target plates of the Mark II and Mark IIGB divertors, which have a higher base temperature $\left(\sim 220^{\circ} \mathrm{C}\right)$ than that of the Mark I divertor $\left(\sim 40^{\circ} \mathrm{C}\right)$. This is fully supported by the results from the specific wall/divertor temperature reduction experiment. As the wall temperature was reduced from 325 to $150^{\circ} \mathrm{C}$, and correspondingly the target temperature was reduced from $\sim 220$ to $120^{\circ} \mathrm{C}$, the impurity sources from both the wall and the divertor target were reduced by $\sim 30 \%$ in the $\mathrm{L}$ mode discharges, which is consistent with the change in chemical sputtering yield predicted by the data from the Toronto group [6]. Consequently, the L mode density limit was increased by $\sim 20 \%$, which further strengthens our argument that the increased impurity production is responsible for the reduced density limit in Mark II and Mark IIGB. These studies strongly suggest that for a carbon based divertor machine the operating temperature must be carefully selected in order to minimize chemical sputtering. 
The elevated divertor source in Mark II led to an increase in $Z_{\text {eff }}$ at the edge, upstream from the target, in the hot ion $\mathrm{H}$ mode discharges, in contrast to the results from ELMy $\mathrm{H}$ modes. The consequence of this for the low recycling hot ion regime is that the loss power from the confined core plasma increases with the $Z_{\text {eff }}$ in the edge, thus reducing the fusion performance in Mark II compared with Mark I. Detailed modelling using the EDGE2D/NIMBUS/DIVIMP codes shows that in the low recycling hot ion regime, the divertor screening for the impurities is poor and chemically produced divertor carbon sources contribute significantly to the core contamination. The changes in $Z_{\text {eff }}$ at the edge for the hot ion $\mathrm{H}$ mode discharges between Mark I and Mark II have been quantitatively reproduced by the codes taking into account the changes in chemical sputtering yields due to the different target temperatures. In contrast, for the high recycling ELMy $\mathrm{H}$ modes, the codes predict that divertor shielding for impurities is strong and the carbon source produced by chemical sputtering at the divertor target makes little contribution to the core contamination (due to the lower energy carbon atoms produced compared with physical sputtering), in agreement with the experimental observations.

\section{Acknowledgements}

It is a pleasure to acknowledge the contributions from the rest of the JET staff. In particular, the authors gratefully acknowledge discussions and support from P.J. Lomas, V.V. Parail and P.R. Thomas.

\section{References}

[1] Reiter, D., Wolf, G.H., Kever, H., Nucl. Fusion 30 (1990) 2141.

[2] Janeschitz, G., ITER-JC Team, ITER Home Team, Plasma Phys. Control. Fusion 37 (1995) A19.

[3] Eckstein, W., Bohdansky, J., Roth, J., in Atomic and Plasma-Material Interaction Data for Fusion (Suppl. to Nucl. Fusion), Vol. 1, IAEA, Vienna (1991) 51.

[4] Roth, J., Vietzke, E., Haasz, A.A., ibid., p. 63.

[5] Federici, G., et al., J. Nucl. Mater. 266-269 (1999) 14.

[6] Mech, B.V., Haasz, A.A., Davies, J.W., J. Nucl. Mater. 255 (1998) 153.
[7] Vietzke, E., Haasz, A.A., in Physical Processes of the Interaction of Fusion Plasmas with Solids (Hofer, W.O., Roth, J., Eds), Academic Press, San Diego, CA (1996) Ch. 4, p. 135.

[8] Pospieszczyk, A., et al., J. Nucl. Mater. 241-243 (1997) 833.

[9] Roth, J., García-Rosales, C., Nucl. Fusion 36 (1996) 1647 with Corrigendum, Nucl. Fusion 37 (1997) 897.

[10] Kallenbach, A., et al., Nucl. Fusion 38 (1998) 1097.

[11] Roth, J., J. Nucl. Mater. 266-269 (1999) 51.

[12] Monk, R.D., et al., Phys. Scr. T81 (1999) 54.

[13] Tobin, S.J., et al., Plasma Phys. Control. Fusion 40 (1998) 1335.

[14] Neuhauser, J., et al., Nucl. Fusion 24 (1984) 39.

[15] Vlases, G.C., Simonini, R., in Controlled Fusion and Plasma Physics (Proc. 18th Eur. Conf. Berlin, 1991), Vol. 15C, Part III, European Physical Society, Geneva (1991) 221.

[16] Matthews, G.F., et al., J. Nucl. Mater. 196-198 (1992) 374.

[17] Guo, H.Y., et al., J. Nucl. Mater. 266-269 (1999) 825.

[18] JET Team (presented by G.C. Vlases), in Fusion Energy 1996 (Proc. 16th Int. Conf. Montreal, 1996), Vol. 1, IAEA, Vienna (1997) 371.

[19] Vlases, G.C., et al., J. Nucl. Mater. 266-269 (1999) 160.

[20] Horton, L.D., et al., Nucl. Fusion 39 (1999) 1.

[21] JET Team, Nucl. Fusion 39 (1999) 1751.

[22] Maggi, C.F., et al., in Controlled Fusion and Plasma Physics (Proc. 26th Eur. Conf. Maastricht, 1999), Vol. 23J, Part I, European Physical Society, Geneva (1999) 23.

[23] Kelly, R.L., J. Phys. Chem. Ref. Data 16 Suppl. (1987) 1.

[24] Kukushkin, A.S., et al., in Controlled Fusion and Plasma Physics (Proc. 26th Eur. Conf. Maastricht, 1999), Vol. 23J, Part IV, European Physical Society, Geneva (1999) 46.

[25] Erents, S.K., et al., ibid., Part I, p. 40.

[26] Schaffer, M.J., et al., Nucl. Fusion 35 (1995) 1000.

[27] Schaffer, M.J., et al., J. Nucl. Mater. 241-243 (1997) 585.

[28] Wade, M.R., et al., Nucl. Fusion 38 (1998) 1839.

[29] Bosch, H.-S., et al., Phys. Rev. Lett. 76 (1996) 2499.

[30] Bosch, H.-S., et al., J. Nucl. Mater. 266-269 (1999) 462.

[31] Finken, K.H., et al., Rev. Sci. Instrum. 63 (1992) 1.

[32] Groth, M., et al., in Controlled Fusion and Plasma Physics (Proc. 25th Eur. Conf. Prague, 1998), Vol. 22C, European Physical Society, Geneva (1998) 361.

[33] von Hellermann, M.G., et al., in Diagnostics for Experimental Thermonuclear Fusion Reactors (Stott, P.E., Gorini, G., Sindoni, E., Eds), Plenum Press, New York and London (1996) 281. 
[34] Bosch, H.-S., et al., J. Nucl. Mater. 241-243 (1997) 82.

[35] Simonini, R., et al., Contrib. Plasma Phys. 34 (1994) 368.

[36] McCracken, G.M., et al., Nucl. Fusion 39 (1999) 41.

[37] Loarte, A., et al., Nucl. Fusion 38 (1998) 331.

[38] Monk, R.D., et al., in Controlled Fusion and Plasma Physics (Proc. 24th Eur. Conf. Berchtesgaden 1997), Vol. 21A, Part I, European Physical Society, Geneva (1997) 117.

[39] Borrass, K., et al., ibid., Part IV, p. 1461.

[40] Guo, H.Y., et al., Nucl. Fusion 40 (2000) 69.

[41] Parail, V.V., et al., in Plasma Physics and Controlled Nuclear Fusion Research 1994 (Proc. 15th Int. Conf. Seville, 1994), Vol. 1, IAEA, Vienna (1995) 255.

[42] Cherubini, A., et al., Plasma Phys. Control. Fusion 38 (1996) 1421.

[43] Langer, W.D., et al., J. Nucl. Mater. 162-164 (1989) 329.
[44] Guo, H.Y., et al., J. Nucl. Mater. 241-243 (1997) 385.

[45] Stangeby, P.C., et al., Nucl. Fusion 28 (1988) 1945.

[46] Stangeby, P.C., Elder, J.D., J. Nucl. Mater. 196198 (1992) 258.

[47] McCormick, G.K., et al., J. Nucl. Mater. 241-243 (1997) 444.

[48] Radford, G., Contrib. Plasma Phys. 32 (1992) 297.

[49] Stamp, M.F., et al., J. Nucl. Mater. 266-269 (1999) 685.

(Manuscript received 27 August 1999

Final manuscript accepted 22 December 1999)

E-mail address of H.Y. Guo: guo@rppl.aa.washington.edu

Subject classification: B0, Te; I0, Tm; J0, Tm 